\title{
The role of mentors in supporting the professional learning of lecturers in further education colleges in Scotland and Wales.
}

\author{
Gary Husband
}

Lecturer in Professional Education and Leadership

Faculty of Social Science, University of Stirling, Stirling, Scotland, FK9 4LA

Disclosure statement:

There are no associated funders with this research. I have no financial benefits or gain arising from this research.

Accepted for publication in Research in Post-Compulsory Education published by Taylor and Francis 


\title{
The role of mentors in supporting the professional learning of lecturers in further education colleges in Scotland and Wales.
}

\begin{abstract}
This article details the findings of a research project that aimed to interpret and understand the experiences of further education lecturers as they undertook initial teacher education. Using rigorous methods grounded in hermeneutic phenomenology, the research situated in colleges in Scotland and Wales structured as two significant case studies, revealed that the 20 respondents had a reliance on both formal and informal mentoring from colleagues in developing their practice as lecturers. The support received from mentors supplemented the perceived deficiencies of formal training courses in preparing the respondents for supporting students with extended needs. The article analyses the relationship between formal university provided teacher education and the practicalities of supported work based practice. The research foregrounds UK further education as a suitable and internationally important model for the broader study of utilised methods of professional learning and the relationships between mentoring and prescriptive qualifications. The paper concludes by highlighting the importance of strengthening and developing mentoring and work based professional learning partnerships within colleges and foregrounds the pertinence of this in relation to the next phase of FE development in the UK.
\end{abstract}

Keywords:

Professional learning, lecturer education, further education, professional formation, work based learning, applied learning, mentors, professional practice. 


\section{Introduction}

This paper is taken from a study conducted over two years between 2014 and 2016. The research aimed to investigate the impact and efficacy of initial teacher education programmes for lecturers working in further education in Scotland and Wales whilst assessing engagement with continuing professional development (CPD) for learning and teaching by exploring the following objectives:

Evaluate the efficacy of models of initial teacher education in post compulsory education by identifying any skills or knowledge deficiencies and areas of confidence as described by respondent lecturers. What factors impact this and how are they related (qualifications, workbased learning and mentors as examples)?

Analyse the effects of initial teacher education for lecturers on individuals' attitudes and approach towards career long professional learning and engagement with further training and qualifications in the field of learning and teaching.

This paper focuses primarily on the first of the two stated aims and explores in depth the findings related to perceived efficacy of lecturer education programmes in Scotland and Wales whilst detailing potential implications for the wider further education (FE) sector in the United Kingdom (UK) and similarly structured sectors in Australia, Canada and northern Europe. The findings detail lecturer's perceptions of deficiencies in training provision, reliance on mentors, impacts on practice and potential challenges for leadership in FE.

This paper has drawn on the detailed and insightful accounts from leading researchers and writers focusing on FE (Orr 2012; Maxwell 2014; Avis and Bathmaker 2004; Canning 2011; Simmons 2008; Lucas and Unwin 2009) and seeks to add to this body of literature by offering the insights of graduates from some of these studied programmes into their experiences and perceptions of efficacy of lecturer education after several years of independent practice. The work presents an original study in that these groups of individuals have previously not been widely studied in relation to the longer term impacts of initial lecturer education programmes, especially and specifically on models and modes of professional learning.

\section{Who are FE lecturers? What does professional formation look like?}

In this next section I discuss the overall professional formation of lecturers in FE. For purposes of clarity, I use professional formation to refer the ongoing process of the gaining of experience, agency, finalisation of qualifications, further professional learning and mentoring. In this sense I am defining professional formation as a process of becoming and forming. It is important to note that this is 
separate to the formal qualification offered by the Education and Training Foundation, Qualified Teaching and Learning Status.

The practice of providing FE lecturer education programmes in the UK has long been held across all the home nations and indeed mirrors many sectors across the world. Various qualifications exist, from post graduate certificates of education (PG Cert) through to teacher qualification (further education) (TQFE) in Scotland. The foundation of these qualifications is similar across the UK, and it is possible to trace much of the course content to a direct correlation with locally applied professional standards (e.g. Scottish PLDF, 2012). University provided courses, offer only one part of the overall package of training commonly available to new lecturers in colleges and it is usual to find online courses, work based assessment qualifications, extended inductions and mentor programmes listed as composite parts of managed and structured programmes. However, as of September 2013 the national requirement in England and Wales for all lecturers to hold an undergraduate or postgraduate level teaching qualification was rescinded following the government sponsored review of professionalism in the FE sector by Lord Lingfield in (2012). The specifications and requirements regarding accepted teaching qualifications was devolved to individual organisations (Institute for Learning 2013) with an expected adherence to published professional standards (ETF 2014) and carrying the expectation that uptake of university level courses would be maintained within the sector. However, a recent report from the Education and Training Foundation (Zaidi, Howat, and Caisl 2017) highlights a downward trend in numbers accessing initial teacher education programmes for FE lecturers in England and Wales. The reduced numbers could be related more closely to the fact that there are fewer lecturers being employed in the sector as well as the removal of the imperative to engage with degree level teaching qualifications; either way, providers of such courses are receiving fewer students. Likewise, the Scottish sector has seen, through the process of regionalisation and continued cuts to funding (Audit Scotland 2015), a gradual decline in engagement with its TQFE provision. Although the Scottish government has not rescinded its policy that all lecturers should be TQFE qualified within three years of starting employment, it has had little or no engagement with national qualifications for lecturers since 2009, and due to reduced funding fewer new lecturers are able to secure financial support from employers to access TQFE. This situation has meant that where funding cuts have been most severe, funds have been diverted from paying for staff qualifications and remitted time to engage with learning.

As a sector, FE employs many vocationally skilled practitioners entering teaching as a second or third career (Avis et al. 2012). These individuals have often already undertaken several years of practice within their specialist fields and have generally gained significant qualifications in their specialist subject areas. It is these qualifications and the industrial based skills acquired through practice, which are required and desirable within FE and needed to teach the broad spectrum of learning and qualifications the sector offers. However, whilst discussing required training and qualifications for FE 
practitioners, the experience of the person bringing those skills and abilities into the FE sector is of significance and importance.

Professional formation over time is more than just an amassing of qualifications; experience and situational competency (Leivisk 2015) are intrinsically linked to practice and take time to develop and become tacit. Gadamer (1998) explores the German idea of bildung (there is no direct English translation but the nearest sentiment could be described as self cultivation or self formation). Using the idea of bildung and the cultural implications that it has for learning, offers an interesting lens with which to inspect the professional formation of lecturers in further education and indeed, it is also a useful basis for the research methodology of this study.

Viewing professional formation as simply the gaining of qualifications limits our understanding of the capacities of a lecturer within FE and detracts from the personal aspects of the individual that are integral to agency and situational competency (Goh 2013) or bildung. Beliefs, desires, personal philosophy (educational and otherwise), political leanings and views, personal life and interests, alongside experience and learning, all contribute towards the continuous formation of the individual, both in personal and professional contexts. These aspects of the person are dynamic and change over time, and with lived and personal experience, so does the person, what we could term as the whole. It would be wrong to view the professional formation of a lecturer in the simplistic and merely as a product of education (training) as that would then imply reproducibility i.e. all lecturers would be the same given qualification $\mathrm{x}$ and experience $\mathrm{y}$. So, in considering professional formation and the continuous process of professional learning, looking at the provision of courses and learning opportunities is important, however, the history and agency of individuals is vital in beginning to understand the processes of professional learning within organisations. Equally it is important to look beyond the formal and taught processes in place within organisations and scrutinise the contextual support for those undertaking learning. As Eraut (2004) highlights, much of what is learned in a workplace is gained through informal interaction with colleagues and peers, that is, what happens outside of formal training is of significance to the professional formation of the individual. Equally, as discussed at length by Cunningham (2007), structured and meaningful mentoring by senior colleagues on a broad range of professional roles and responsibilities is crucial to the overall process of formation. Frequently the importance of such relationships is overlooked, and in the midst of austerity driven reform there is the risk that time for mentors to focus on the needs of junior colleagues, will be driven from the system by efficiency savings.

In undertaking to understand the processes and complex systems of learning in professional formation, reviewing the provision, structure, design and teaching methods of programmes will only yield information related to efficacy and impact on a superficial level. The experiences of the individuals, the resultant change to both themselves and their professional practice as a result of engaging with the programme of learning and those that provide and support it, that is, not just what 
was learned but also how the individuals were changed, and how individuals continued to change as a result, will yield a much greater depth of understanding of the effect of programmes of learning. This is a complex process formed of several important factors and cognisance of formal learning programmes, work based learning (Maxwell 2014), mentoring (Cunningham 2007), individual agency (Goh 2013) and informal professional learning (Eraut 2004) is essential in forming an understanding of how professional learning impacts individuals and is useful or otherwise in practice.

\section{Study Design and Research Framework}

This study was designed to develop an understanding of the long term efficacy and impact of initial lecturer education programmes by developing two case studies focusing on the systems in place in two colleges and by capturing the experiences of respondent lecturers.

\section{Theoretical Framework:}

Careful design and rigour coupled with a plan of investigation utilising methods that align with the chosen philosophical paradigm is crucial in the production of valuable research that stands up to academic scrutiny, and is useful to the community accessing it (Bradshaw and Stratford 2010). In considering the qualitative design of the research project, and keeping a focus on the stated objective of seeking to understand experiences as described by respondent lecturers, various approaches were considered.

Initially focusing on phenomenology (Laverty 2003) as a means of interpreting the experiences of the members of the community was favoured but further study of this methodology highlighted a conflict that required recognition and careful consideration. Phenomenology requires the researcher to step outside of the recounted experiences and form a subjective view of the essence of the collective experiences of the respondents and 'bracketing' the experiences and preconceptions of the researcher (Simon 2011). Given that the researcher worked for several years as a lecturer in FE and underwent the same training as many of the respondents, it was considered that not acknowledging this position would provide detriment to the authenticity and academic rigour of the research.

Considering further the position of the researcher, methods grounded in hermeneutic phenomenology (Age 2011) were considered appropriate in establishing and understanding the experiences of individual respondents. Hermeneutic research allows for the valuable insights of the researcher to be acknowledged (van Manen 1990).

Gadamer $(1998,295)$ states:

"Hermeneutics must start from the position that a person seeking to understand something has a bond to the subject matter that comes into language through the traditionary text and has, or acquires, a connection with the tradition from which it speaks" 
Recognition that a bond exists between the researcher, the respondents and the subject matter, allows for the consideration of researcher personal insight, experience and values in interpretation of the recounted experiences and feelings of the respondents (Laverty 2003).

\section{The colleges}

Two colleges of further education participated in the study. The study was a non-funded project and as such had limited resources with which to engage large numbers of respondents, thus in order to generate sufficient data to facilitate the required depth of analysis, it was decided to conduct a two case study site project carried out in different countries within the UK. The large, similarly structured colleges, working in devolved regions of the UK provided ample opportunities to secure respondents and study the different but related methods utilised to provide initial lecturer training and continued professional learning. I had worked in both the Scottish and Welsh FE sectors and as such had specific knowledge of both devolved settings, policies, practices and curriculum demands. Selecting colleges from different areas of the UK presented the opportunity to sample organisations working towards similar curriculum with similar staff demographics but in different policy contexts. Studying two colleges situated within the same devolved locale may not have provided the same opportunity to sample such a diverse set of documents, respondents, policies and practices within the bounds of a limited sample size.

Selecting colleges of a similar size, sector position (quality inspection outputs, student numbers, staff roll call) and curriculum were important features of the research design. The colleges were matched as evenly as possible to ensure that the pressures, conditions and requirements were comparable.

Although the aims of the study did not include a requirement to report on comparisons and form judgements, an inevitable part of the research was to report on form and structure within organisations. This was limited to a non-judgemental reporting of the situation observed but did ultimately lead to comment being made on the differences between the impact of the processes employed in the different colleges and their relative effect on respondent's learning and engagement.

Agreement was secured from college 1 in Wales which was used to match college 2 in Scotland. As was almost inevitable within the FE sectors in Scotland and Wales at the time of study, both colleges had been engaged in separate but major government driven merger processes. The current institutions were the resultant organisations that had emerged from merger between (in both cases) three separate colleges. College 1 had completed its merger 2 years prior to this research and for college 2 in Scotland, only 1 year had passed since the formalisation of the merger process. However, the stated dates of merger represent only the formal dates of signing and incorporation of the new organisations, in reality, the merger process had involved several years of negotiation prior to formalisation and in 
both colleges, rationalisation, streamlining and finalisation of processes and systems at all levels was still very much at the fore and as yet, not completed.

It is beyond the scope of this paper to comment on the efficacy of the merger strategy within individual colleges in meeting these desires, however, it is noted that these large scale undertakings have had significant impact on the working lives of many of the staff working within the respective colleges and as such, an impact on the results of this research.

Both studied colleges operate over multiple campus sites and serve in excess of 15,000 students each. Over 1000 staff are employed in both respective colleges covering all areas of operation, including teaching. Curriculum offerings are typical of large multi campus FE colleges comprising of a large range of specialisms, including the arts, social sciences, technology, health and care, access courses and a broad range of vocational and day release studies covering from school through to university academic levels. Many areas of study are rationalised into regional centres, examples such as Engineering and building crafts have their own (largely) dedicated buildings in both colleges.

Geographically, the Welsh college covers a very large area of Wales including urban and rural settings. The student population is made up of individuals from diverse demographics from some of the most deprived and affluent post codes. The Scottish college covers a smaller geographical area but covers a major urban centre in Scotland. Students of the Scottish college are very diverse, and once again, represent some of the most affluent and deprived post code areas in Scotland.

\section{Respondents}

A named contact in both colleges holding a senior executive management position circulated the call for research volunteers within the respective organisations. From the responses sent expressing interest, all were invited to take part. The criteria within the circulated information stating that all initial training should have been completed and at least 3 years of teaching practice completed, was met by all 24 initial responses received between the two colleges. Two people from each college chose not to continue due to workload and timing issues, and on communication to arrange interviews, formalised their withdrawal.

The final twenty respondents included only individuals that were in current and active roles that included timetabled teaching. The respondents were all between 28 and 58 years of age, and of the 20 engaged respondents, 10 were male and 10 were female. Three of the respondents, although still actively engaged in teaching at the time of interview, held promoted posts with both line management of lecturing staff and curriculum management responsibilities. A range of subject specialisms were represented within the sample and although not specifically required or sought, a representative sample of several key subjects (across the arts, social sciences, technology and humanities) was 
desirable and achieved. Every possible opportunity was taken to ensure a representative sample of the lecturing community was engaged in the research. In Wales, all communication was bilingual and if required the opportunity to have information in English and Welsh in audio format was available.

\section{Interviews}

Using a methodology influenced by the principles of hermeneutic phenomenology (van Manen 1990; Watson 1971; Heidegger 1962; Gadamer 1976), semi structured interviews were used to engage respondents in reflective conversation with the expressed aim of capturing the professional experiences that had influenced and formed the opinions and lives of the respondents related to both work and the choices that had led them to teaching. The interviews were structured around questions that initially focused on career formation, prior experiences before teaching, where respondents were from culturally and geographically and how they had arrived in their current working position. This was undertaken to capture the richness of the individual, form a connection between the person and the professional persona and practice and provide context to subsequent questions focusing on specific learning experiences.

As the individual interviews progressed, the questioning moved onto addressing specific learning events within the respondents teaching careers, namely those that the employing organisation had identified as affording the individual 'fully qualified' status upon completion. The questions asked respondents to focus on what they felt were the most relevant and useful aspects of their learning in relation to their role as an educator and lecturer. These questions led onto a focus on which aspects they understood, after several years of practice, to have been least relevant or useful in their subsequent teaching career. In this vein, the questions then moved onto asking respondents where they felt they would have liked greater tuition and focus in their initial courses of learning, the influence of mentors and informal workplace learning. Finally, the questions moved onto looking at longer term impact on the respondent's careers of their engagement with initial professional learning, choices of continued professional learning, impact on identity and potentially transformative experiences in education. The questioning process was designed to guide respondents through their reflective account and form a coherent transition through career stages, experiences and learning. As the interviews progressed and areas of thematic interest emerged from the data, the interview questions were supplemented with additional lines of enquiry that were designed to elicit more data specific to the emerging fields of interest.

Emotional and non-verbal responses coupled with environmental data was also captured in accompanying field notes and used in the analysis of responses alongside the narratives given in response to questions and prompts. Using the semi structured interview enabled respondents to talk freely and relax as if in conversation. Where prompts were needed they were subtle and as much 
space was allowed for thought and reflection as possible. In the recordings of the interviews the spaces and pauses for thought frequently revealed as much as the answers and reflections themselves. This process allowed for individual agency and personal experience to be shared in conversation, explored and recognition given to emotive responses as they revealed areas of stress or frustration in practice (Drever 2003; Yin 2011).

As the interviews were designed and conducted in such a way as to prompt critical reflection and could potentially elicit emotive responses, it was ensured that the BERA (2011) (now updated to BERA 2018) ethical guidelines formed the central premise around which respondent interaction, data analysis and reporting was designed and conducted. Informed consent from respondents prior to engagement with interviews was sought and secured. Prior to commencement of each interview all respondents were again reminded of the focus of the research, the areas of questioning and the fact that they could not answer questions if they chose, stop the interview at any time and withdraw at any point should they choose. No questions were refused, no interviews were stopped and no respondents withdrew at or after the interview stage of the research.

\section{Document analysis}

A document analysis related to programmes of professional learning was undertaken to establish an accurate understanding of the models of learning offered and provided by each organisation. Upon request, initial and career long learning programme plans, college training policies, organisational development strategy, quality enhancement and assurance policies, online learning and induction models and induction event plans were all provided by the participating organisations. The documents, alongside the testimony of the managers in these areas (where needed for clarity) were used to reconstruct the expected training model that each new member of staff would follow. These programmes were compiled from induction and ongoing professional learning plans that staff in each organisation would theoretically be expected to follow.

This analysis was undertaken to ensure that the researcher was completely aware of the specific requirements of each of the respondents in relation to their professional learning. By cross referencing interview and documentary data, it was also possible to determine how the programme of professional learning had been implemented for each respondent and what learning they had been expected to achieve. This gave specific insight into whether respondents had been able to access all of their planned training (in relation to the published organisational model) and whether access to expected courses and provision was restricted or removed. It should also be noted that this research was conducted during a time of significant change within both colleges and as the research was concluding both organisations had begun the process of finalising their various programmes of staff training and support post-merger. The final programmes were not available at the time of the field work and no indication was given as whether the changes were significant or minor, however, anecdotally an 
indication was given that new formal programmes were based entirely on the legacy provision represented here. This has no impact on the research results as each of the respondents had completed their training and any new programmes would not impact them.

The document analysis was a valuable part of the research as it provided specific context and provided rich data based on documents that existed prior to the project commencement, thus yielding information that was fixed and free from researcher influence and bias (Bowen 2009).

\section{Data Analysis}

Interviews:

The analysis of interview data using a framework of hermeneutic phenomenology took several steps. An emersion within the data was sought and occurred incrementally and progressively as more data was gathered (Crist and Tanner 2003). The acknowledgement of forefront knowledge, experience and researcher horizon (Gadamer 1998) guided the process of analysis as the researcher used personal histories to begin to contextually frame and understand the stories and experiences of the respondents. The first two of the interviews conducted were treated as pilots with feedback from respondents used to modify the order of the questions, the framing of the enquiry and the pace of progression through the areas of interest. By undertaking pilot interviews and modifying the questions as the research progressed, it was possible to focus on areas of importance and concern that emerged from the data, consequently, analysis began and occurred from the outset of the fieldwork. Although an interview schedule was written prior to engaging with respondents, the research questions evolved as areas of specific interests and themes emerged. As an example, it became clear through the first two interviews via the emphasis placed on it by the respondents that the role of the mentor should be explicitly explored and not left to chance emergence. On concluding the interview process it was possible to merge existing analysis and coding with the entire data set and subsequently analyse all the gathered interview data together. It was possible to carry out a thorough analytical digital coding process using Nvivo 10 software to manipulate and section the audio recordings of the interviews. Grouping and regrouping responses within the 15 hours of recorded data aided in the identification of keywords, phrases and responses and allowed for continuous emersion and analysis not only of the words being spoken but also hesitation, emotion and prolonged silences. As an example of this process, Diagram 1 shows how these key phrases emerged related to the most valued aspects of initial lecturer education, in the opinion of the respondents. 
Diagram 1: Practical and vocational exercises were the most valued aspects of training.

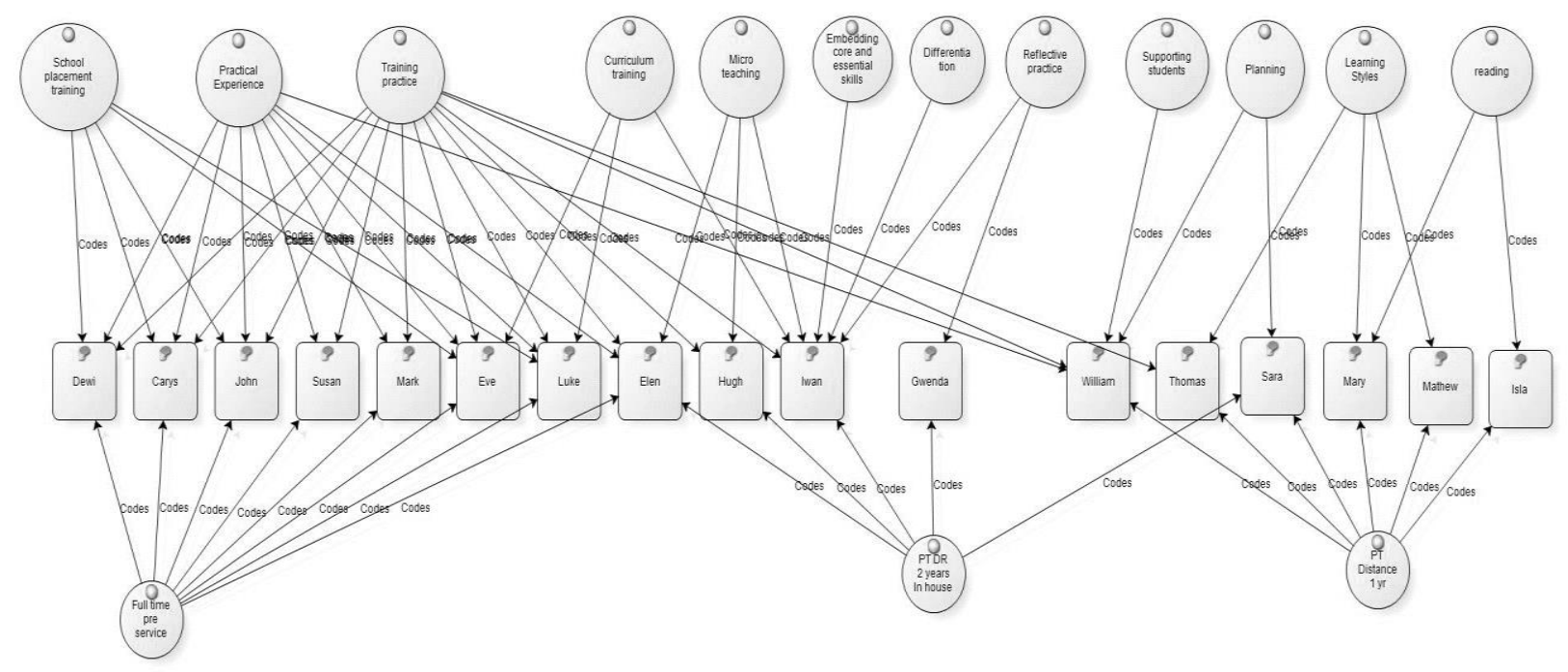

\section{Documentary analysis:}

The documentary analysis focused on document artefacts related to the support for and provision of training for new lecturers.

When the relevant documents requested of the colleges had been received (not all were supplied) analysis commenced by grouping and numbering documents. Several sessions of reviewing the documents allowed for a picture to emerge of the outlined programmes and structures of professional learning in both participating colleges. The purpose of the exercise was to ascertain what mandatory training requirements employees of each organisation were expected to meet and, how they were facilitated in achieving their conditions of employment in relation to training. A further aim of the exercise was to fully map the differences between requirements and documented training programmes and what happened to employees in training.

This process also included a full analysis of the various and local professional standards related to teaching and learning. This was undertaken to begin to trace the elements of training programmes to their origins in the relevant national standards and used to map both colleges' complex training programmes to each other.

There was no expectation either of compliance or non-compliance with published plans but a reference frame was established to begin to understand the realities within each organisation. Where gaps in information were identified then clarification was sought from curriculum leaders and managers responsible for the studied areas. A further aim of this document analysis was to provide a benchmark for what each organisation deemed to be the requirements of teaching staff to be considered as fully qualified. By a continuous process of cross referencing between document types 
(e.g. published college policy and training programmes), it was possible to fully construct an accurate model of the variables within the training programmes between the two organisations.

\section{Results}

In this section I will detail both the findings from document analysis and interviews. Using the document analysis results to provide a contextual understanding of the expectations placed on trainee lecturers, I will detail the main themes that emerged from the interviews and focus on two key areas, mentoring, and identified skills in which respondents reported a lack of confidence. Respondent voices are used to provide depth and nuance to the reported results with accompanying commentary on emotive and physical responses to questions used to provide further underpinning context to the reporting of the spoken words. All names are pseudonyms.

\section{Document analysis:}

The document analysis results revealed the published and planned structures of the intended programmes of initial training in both studied colleges. There was little difference between the two stated models in the content and structure of the programmes but greater emphasis was placed on different aspects of training by the different organisations. Academic courses at graduate level were delivered in house and under license from a university in the Welsh college, and completely externally by university partners for the Scottish college. The Scottish college was still using a blend of legacy policies as it was still rationalising provision post-merger. However, all legacy articles were almost identical and the planned training for all candidates had remained unchanged for many years. 
Table 1: Published training models of the studied colleges ${ }^{1}$

\begin{tabular}{|c|c|c|c|}
\hline \multicolumn{2}{|c|}{ Welsh college } & \multicolumn{2}{|c|}{ Scottish college } \\
\hline Activity & Details & Activity & Details \\
\hline Induction & $\begin{array}{l}4 \text { months of scheduled } \\
\text { events centrally managed }\end{array}$ & Induction & $\begin{array}{l}6 \text { months of scheduled events } \\
\text { centrally managed }\end{array}$ \\
\hline Probation & $\begin{array}{l}2 \text { years. Completed on final } \\
\text { award of PG Cert }\end{array}$ & Probation & $\begin{array}{l}1 \text { year, not related to } \\
\text { qualifications. }\end{array}$ \\
\hline $\begin{array}{l}\text { Statutory } \\
\text { compliance } \\
\text { training }\end{array}$ & $\begin{array}{l}\text { Online modules in: fire } \\
\text { safety, manual handling, } \\
\text { vulnerable person } \\
\text { protection and equality and } \\
\text { diversity }\end{array}$ & $\begin{array}{l}\text { Statutory } \\
\text { compliance training }\end{array}$ & $\begin{array}{l}\text { Online modules in fire safety, } \\
\text { manual handling, vulnerable } \\
\text { person protection and } \\
\text { equality and diversity }\end{array}$ \\
\hline $\begin{array}{l}\text { Academic } \\
\text { Learning }\end{array}$ & $\begin{array}{l}\text { Professional graduate } \\
\text { certificate of education } \\
\text { (PGCE or PGCert). } \\
\text { Delivered in house under } \\
\text { license from partner } \\
\text { university. } \\
\text { Contractually obliged to } \\
\text { complete within 2-year } \\
\text { probation }\end{array}$ & Academic learning & $\begin{array}{l}\text { Professional Development } \\
\text { Award (delivered in house) } \\
\text { and/or } \\
\text { Teacher Qualification Further } \\
\text { Education (TQFE) (delivered } \\
\text { by externally by university } \\
\text { provider/s } \\
\text { National obligation to } \\
\text { complete within three years } \\
\text { of commencement of } \\
\text { employment. Compliance } \\
\text { poorly monitored. }\end{array}$ \\
\hline $\begin{array}{l}\text { Non-academic } \\
\text { learning }\end{array}$ & $\begin{array}{l}\text { In house supplied systems } \\
\text { and processes training, } \\
\text { No requirement for } \\
\text { Assessors award training. }\end{array}$ & $\begin{array}{l}\text { Non-academic } \\
\text { learning }\end{array}$ & $\begin{array}{l}\text { In house supplied systems } \\
\text { and processes training, } \\
\text { Assessors award } \\
\text { Assessment verification } \\
\text { awards }\end{array}$ \\
\hline $\begin{array}{l}\text { Work based } \\
\text { practice }\end{array}$ & $\begin{array}{l}\text { Subject specific mentor, } \\
\text { and line manager supported } \\
\text { programme of meetings, } \\
\text { team teaching and } \\
\text { observations. } 2 \text { year } \\
\text { programme. }\end{array}$ & $\begin{array}{l}\text { Work based } \\
\text { practice }\end{array}$ & $\begin{array}{l}\text { Named part time mentor } \\
\text { related only to qualifications } \\
\text { (i.e. PDA and TQFE) } \\
\text { No teaching observations are } \\
\text { undertaken. }\end{array}$ \\
\hline $\begin{array}{l}\text { Remitted time for } \\
\text { learning }\end{array}$ & $\begin{array}{l}\text { Yes, } 10 \% \text { teaching } \\
\text { allocation reduction for first } \\
2 \text { years of employment. }\end{array}$ & $\begin{array}{l}\text { Remitted time for } \\
\text { learning }\end{array}$ & No \\
\hline $\begin{array}{l}\text { Novice status of } \\
\text { new employee }\end{array}$ & $\begin{array}{l}\text { Contractually recognised as } \\
\text { trainee for two years }\end{array}$ & $\begin{array}{l}\text { Novice status of } \\
\text { new employee }\end{array}$ & $\begin{array}{l}\text { Not recognised. Full teaching } \\
\text { allocation from start of } \\
\text { contract. }\end{array}$ \\
\hline
\end{tabular}

\footnotetext{
${ }^{1}$ The respondents had all been through their initial training at different times and as such some specifics such as course provider or the availability of mandatory health and safety modules as online automated packages had changed. However, it was possible for all to recognise comparable elements and levels within published programmes.
} 
Table 1 (above) details the training programmes that were theoretically required to be undertaken by new teaching staff in both organisations. Although there are differences in structure of initial training related to time scales and emphasis, they largely match in terms of planned content and scope of coverage. Significant differences appear in the status afforded to those undertaking training courses. The Welsh college contractually recognised novice status both in terms of required teaching load, remitted time for learning and remuneration. This further impacted on available time for study, trainees in the Welsh college were given a day a week to attend their university provided course where those in Scotland had to study entirely in their own time.

Respondents were shown during their research interview the training model of their relevant organisation and asked to comment on how it resembled their own provided training. All respondents agreed that the model presented to them was the same as the model that they had been told they would undertake upon starting employment. However, where the graduates of the Welsh college training programme were also in agreement that they had been availed of all aspects of their planned learning, none of the graduates of the training programme in the Scottish college agreed that they had been able to access their complete programme within the stated timescale of three years. Emphasis had been placed within the Scottish college on making sure staff had undertaken to complete work based assessors and verifiers awards and these were seemingly afforded proxy status for teaching qualifications.

\section{Mentors and mentoring}

In this section I detail the results related to the formal and informal support in the form of mentoring and colleague activity within the colleges.

The research initially set out to test the efficacy of university provided courses in Scotland and Wales in supporting the professional formation of lecturers. The interviews quickly revealed that respondents placed much greater value on their situated learning than had been anticipated, this meant that in interviews a greater focus on the work of mentors and the support they provide for work based and focused learning was required. As will be explored in some detail, respondents repeatedly identified the work of formal and informal mentors as critical to their development.

The college in Wales was found to have a greater investment in its mentoring activities. Mentors were trained by in house providers and a fully structured programme of meetings, discussion points, team teaching and developmental observations was planned and documented for the first two years of trainee employment. Each stage was signed off by the trainee's line manager, mentor and presented as summative evidence in the final portfolio of the PG Cert. Mentors were considered to be suitably experienced and qualified after they had completed their own initial training and undertaken several years of practice and had leadership responsibilities (year groups or course management). Information 
was provided that several individuals within the college had been supported to complete postgraduate study in mentoring, however, this was not a universal requirement.

Specific figures for the numbers of active mentors was unavailable but it was thought that an ane time there would be in excess of 50 trainee lecturers within the college, each of whom could not study PGCert without a named mentor. Mentors did not normally work with more than one trainee at any one given time.

The Scottish college had recently undertaken a significant merger and as such at the time of analysis it was difficult to ascertain what was available to new employees and what was either legacy related (to one of the pre-merger colleges) or aspirational. The organisation had had several well documented issues undertaking merger and as such, much policy was still under negotiation. However, much of the planned programme of professional learning for new employees was clearly documented and had individuals undertaking learning. Significant differences from the college in Wales were few but evident. The mentors in Scotland were deployed very differently. There were 4 part time lecturers acting in mentoring roles, each with some responsibility for a group of lecturers undertaking either professional development awards (PDA) or TQFE. There was no programme of mentoring events outside of the requirements of the qualifications and the mentors themselves had upwards of 15 mentees each and were not specific subject specialists i.e. they were lecturers in education and not senior departmental colleagues. Each mentor had undertaken postgraduate learning in mentoring and had many years of experience as a lecturer in FE, and were all still teaching their own subject specialisms for the remainder of their fractional contracts.

The role of the mentor in each organisation and their impact on the learning of trainee lecturers was found to be positive, and despite the differences in operation and deployment, no major differences in quality, engagement, dedication, or expertise were evident in responses from participating lecturers. Issues surrounding availability and workload were foregrounded by document analysis and in interviews. The four part time staff were tasked with providing mentoring support to over 70 individuals at the time of site visit. This method of operation was common to all of the legacy colleges in the newly merged organisation and had been the same for many years.

Of the twenty interviews undertaken, 16 commented positively and directly about their experiences with mentors. Comments referencing mentors were overwhelmingly positive.

William who teaches a technical subject in the college in Scotland and had come to teach in FE after a long career in industry, was particularly focused on his experiences of training. Although offering some criticism of the lack of subject specific focus William praised his mentor:

I can't believe they [mentors] do it part time? I suppose it's good in a way 'cos they're still teaching but it's tough on them. I couldn't have done my TQFE without Sue [not real name] she was excellent. The distance learning [of the TQFE] wasn't really ideal for me, I like to be with people when I'm learning, I could talk to Sue about course stuff and I learned more from her really. 
William spoke passionately about his mentor and was visibly pleased to be able to praise her commitment and knowledge. It was clear from William's emotive response that his mentor had had a significant impact on his professional practice and training experiences.

Similarly, Bryn who was in his 50s and teaches a social science focused curriculum in Wales also offered a positive assessment of his experiences:

The PGCE was OK, too much emphasis on theory and not enough practical help. I enjoyed it but that's because I got lucky with the tutors, they were more like mentors. I was in my 50s when I trained and didn't need help with writing essays, I wanted help with actual teaching. Ha ha, they were surprised when they came to one of my classes and were quick to help. I had a mentor in the department who was also good to be fair. It was the people who trained me really, not the course, if that makes sense?

Bryn was supremely confident as an individual and was very clear and precise in his responses to questions throughout the interview and was quick to offer critique where he felt necessary, the praise for tutors and mentors here was genuine and heartfelt.

Although given different prominence and deployed and managed differently in both organisations studied, it was clear from the responses given that the respondents frequently viewed their mentor to be a primary source of information, practice based support, role models and trusted critical friends. The relationships with mentors had brought about change in both practice and values of the trainee lecturers which came through in their responses related to preparation for teaching practice.

However, not all mentoring was centrally managed and it was reported by one of the respondents in an early interview that they had relied on colleagues to informally mentor them. Subsequent interviews with respondents sought to enquire as to whether this was a more widespread phenomenon. All subsequent respondents (14) confirmed that they had benefitted greatly from colleagues offering informal support and guidance.

Luke who was trained in Scotland and now teaches in a different college from that in which he started his second career, voiced quite clearly both his gratitude and concerns about having to rely so heavily on colleagues in his early days as a lecturer:

(breathing out heavily) it was really tough, the first few days I really thought about jacking it in. I had a confusing timetable of classes all over the place and (laughs) I had no idea what a module or curriculum was, I had to crack on with it. There were a few great people about then and they got me through, it was probably short cuts and maybe not the textbook way of teaching but it worked. Its worrying that I have to do that sort of thing for new folk now.

Similarly Elen in Wales who has been teaching law for over 5 years after a distinguished career in the legal system, expressed her gratitude for informal mentoring and conveyed her desire to emulate this behaviour: 
I don't think anyone gets through the first few weeks without good colleagues, I was knocking on doors all the time and asking how to do this or whatever. I think that is just how it works, you need people around you to show you how they do it. Most people were alright with that, I guess like I am now, or try to be.

The respondents from the college in Wales highlighted that their teacher education courses had left them with a need to know more about the practicalities of managing potentially difficult situations in the classroom or workshop. Interestingly, many who made this observation then highlighted that they had relied on a good mentor or indeed as mentors could provide this support. This same support was not as widely reported in the Scottish college even though mentors were praised it was acknowledged they were overstretched and there were too few to cover the needs of the many trainees. The mentors were clearly acting as mediators between all aspects of training, often within practice, and certainly, were providing more support than had been anticipated by the trainee lecturers.

\section{Preparation for teaching practice:}

In this section I focus on the findings of the interviews detailing the practicalities of teaching and the aspects of practice which respondents identified as requiring greater support in training and professional learning provision.

Classroom management, managing challenging behaviour, classroom delivery, managing teaching practice and student behaviour were all identified multiple times by respondents as areas of concern or for discussion. Reported behaviours of concern ranged from mild noise related disruption through to physical violence and the need to restrain students (although very rare). Many respondents informing the research work reported teaching on a daily basis a broad range of demographics including school children, adults with additional support needs, looked after teenagers and individuals with specific learning support needs who have had previously poor experiences of education. These complex groups with a broad range of complex needs are representative of the broader community accessing FE and are to be found in almost every college of further education in the UK, the sample colleges in this respect were entirely typical.

These concerns and areas identified as requiring greater attention and focus in training courses are all closely related and specific to applied and vocational practice in the teaching environment, that is, they are extremely difficult to effectively emulate in training situations.

The questions to respondents in this section of the interview focused on identifying which were the most influential and practically useful aspects of training courses (Diagram 1), which areas covered by training were least useful in practice and, given the opportunity, what would have been studied in greater depth. The strong theme that emerged in response to this line of enquiry is related to the importance placed by lecturers on practical training in the classroom, specifically for dealing with high stress situations such as those related to the behaviors and support needs described above. 
The desire to learn and develop the ability to undertake the basic principles of the role of lecturer and be confident in teaching practice repeatedly came through in the interview responses.

Mathew, who teaches a practical and technology based curriculum in Scotland was enthusiastic in his responses and shared the following thoughts:

I fell into teaching as most people in colleges do, I came from an industry background and had no idea about the theories and background of teaching, and I guess that is where the university side of things came in. There should really be a much better way of giving practical training in the college that helps with every day stuff like poor behaviour and emotional difficulties. I had no help with that and relied on my experiences with apprentices where I used to work.

Mathew highlights the individual agency of the diverse and eclectic community of practitioners teaching in FE. Many of the required skills for teaching are perhaps already present in many new colleagues entering FE and Mathew here points to the importance placed on practical training by the respondents.

Hugh who delivers business studies and trained in Wales identified managing challenging behaviour and general classroom management as being of specific importance to lecturers:

I felt that there was very little in the way of classroom management training and there should have been a lot more of it to help with dealing with difficult students, in this way, I felt that the course did not get you classroom ready. Luckily I had a good mentor and to be honest, they taught me most of what I needed and helped with my confidence.

Hugh's answer was immediate and clear which was the case for all respondents in relation to this question. The identification of the need to have further and ongoing training in managing challenging behaviour and classroom management was consistent. Little definition was made between classroom management and managing challenging behavior, the respondents seemed to equate one with the other. The respondents again identified the importance of consistent and strong mentor relationships in dealing with an area they had assumed would be dealt with formally in study.

Thomas, who trained in Scotland and teaches a broad range of engineering related courses, placed a similar level of importance on classroom management training:

There should have been much more training on working with people, class control and support, whenever it was raised [in training] we were just told by the lecturers to not get involved.

Thomas goes a step further in his response and identifies that some aspects of training related to managing the teaching environment and groups of students were actively avoided during his training. 
There is a concern amongst the respondents that they had not received sufficient training through initial teacher education courses in managing difficult or challenging classroom situations. This theme emerged quickly from the interview data and was at the forefront of many of the respondent's minds. The responses related to efficacy of training and the most useful aspects of courses were nearly all focused on the benefits and usefulness of applied and vocational learning in relation to the practicalities of teaching and specifically, avoiding and managing challenging behaviours perceived as negative and disruptive. The respondents universally represented a supportive and caring stance in their concerns and were entirely focused on helping students with difficulties and not developing skills in crowd control or discipline.

Here again, the role of the mentor both formal and informal emerged from the data as important. Respondents identified again how mentors were relied on to either support the learning or fill in the perceived gaps in knowledge and experience.

\section{Discussion}

In this next section I discuss the substantive findings and the subsequent importance of both formal and informal mentoring. The discussion will explore these central themes and detail their significance in relation to the perspectives of the respondents and the related programmes of professional learning.

Whilst recognising the paucity in the research literature, Maxwell, drawing on the work of Finlay, 2008; Lucas and Unwin, 2009; Orr and Simmons, 2010 and Avis et al, 2011, identified five specific areas of importance in training practice that support trainee lecturers and promote learning and development cultures within colleges. The focus on the learning and training of lecturers in applied and vocational settings and specifically the learning in the work place, is emphasised and identified as being significant. Maxwell (ibid) highlights the benefits of professional work based learning with a positive connection between training in partnership with a university with specialist staff and courses. Attention is drawn to the importance of the employing institution recognising, supporting and affording a novice status for trainee practitioners with genuine cultural and community engagement (this draws on the work of Engestrom, 2001 and Wenger \& Lave, 2002). This in itself adds further significance to the importance of mentoring within these programmes as the individualised and the contextual learning was amplified through the encounters with experienced colleagues.

The document analysis of the programmes of learning for trainee lecturers in both studied colleges, reveals that each system has many of the important factors described by Maxwell (ibid). Each organisation recognises work based practice within its adopted and published model. Each college chose to implement and manage this differently, demonstrated by the differing roles of mentors in each college. Common to both organisations was a recent and continued downward trend in funding 
provision which seemed to have impacted the work of professional learning mentors by limiting time available and numbers of individuals able to provide support. Interestingly, non-formal or informal mentoring from colleagues played a critical role in the professional lives of those who recalled their experiences. It is not surprising that informal mentoring plays an important role as Woodd (1997) argues, mentoring activities in organisations should not preclude the work of informal mentoring in leading to individual learning. However, in the Scottish college due to the remote nature of the mentors and their caseload being in excess of 15 candidates each, the informal aspects of learning were covering more than the stated plan showed. It was revealed by respondents that much of their professional learning and early training was supplemented by the guidance of experienced colleagues. Although the value of this is recognised, there are two important factors to acknowledge. Firstly, the respondents were all qualified and continuing practitioners with significant post training experience in teaching. That this particular group placed so much emphasis on the value of mentoring is important as it suggests that these relationships, founded in training, were important, significant and valuable. They were instrumental in the professional learning of the respondents but also factored in the cultural and practical induction suggesting that the mentoring relationships were able to perhaps shape cultural dimensions within the college. Although programmed and required, the impact of mentoring on these candidates, seen through the lens of experience and practice was possibly far greater than anticipated in the detailed programmes identified through document analysis.

The findings of this research in relation to the desired areas of greater depth in training as reported by the respondents suggest that there is a need to re situate the developmental context of much of the learning of trainee lecturers and strengthen the links to practice (Goh 2013). Mentors emerged from the data as the links in the system and the focus of much of the success of the programmes of training. The mentors in both organisations had some responsibility for supporting the applied learning of their colleagues and this offers an interesting finding in relation to the depth of the roles taken on by those acting in both official and unofficial mentoring capacities. As discussed at length by Coffield, Moseley, Hall \& Ecclestone (2004) teaching individuals how to cope with and manage the multiple challenges presented by students from diverse and often difficult backgrounds, is fundamentally challenging in itself. Multiple variables and changing dynamics within groups make standardised tuition for trainee lecturers in these areas identified by respondents as important, but also difficult to emulate in training scenarios beyond those of actual real supported experience. Once again the role of mentors in these scenarios demonstrates their importance in helping both trainees and post training lecturers to piece together the multiple factors of the programmes of learning being undertaken. Returning to the idea of bildung (Gadamer 1998), these relationships, as opposed to the qualifications, may be the more active part in facilitating self-actualisation. 
Respondents variously identified issues such as, being told not to get involved where students were presenting serious challenges to accepted behaviour standards, having to wait many years to access training and struggling to reach a mentor for advice (although praised for their difficult job). These issues all point towards some deficiencies in the college provided support structures for novice lectures which were frequently being filled by the benevolent actions of peers. Although peers were frequently experienced and very capable lecturers, by the admission of the respondents, their advice may frequently have pointed towards shortcuts or strategies that worked for them personally. Strategies and methods are not universally transferable and as such many of the respondents found themselves having to muddle through and find their own solutions, thus leaving them open to feelings of uncertainty and incompetence related to some important areas of practice. This finding was more prevalent in the Scottish college where the mentors were very stretched in relation to time and caseload and were frequently operating on multiple campuses. This serves to highlight that although well-meaning and altruistic colleagues provide valuable support, there is a danger to the learning of lecturers where organisations have an over reliance on this learning, or indeed, provide insufficient mentoring support thus forcing trainee lecturers to turn to their colleagues.

\section{Conclusion}

The realities and experiences of the respondent lecturers offer useful insights into the priorities and stresses related to professional practice in the FE sector. The colleges studied were typical of their size and region and the respondents offered an excellent sample of the cross section of the communities within these colleges. The findings of this research shed light on some interesting and important issues that are transferable across sectors and organisations.

This research has shown that there is an identified need to focus on how the learning and development process for lecturers can incorporate greater support in managing multiple challenges and dynamics in the live working environment. Finding a balance between the work of mentors, formal courses of learning and informal mentoring appears to be of critical importance. The respondent's experiences of both learning and practice begin to show that the efficacy of the overall training model in preparing individuals for college teaching practice is not dependent on the academic learning alone, but also on the relationship between different aspects of training programmes, college provided support and departmental practices. This is an important and challenging issue as it points directly towards the responsibility for the professional formation of lecturers lying directly within the employing college and not solely with university partners providing the academic qualifications that are seen to represent fully qualified status.

Although there are often effective strategies in the design of university provided courses to situate learning in practice, but, as they are external providers, the universities cannot supply solely or fully 
work based courses and indeed, they should not try to. As such the university partners, cannot completely address the respondent identified deficiencies in the practicalities of the more challenging aspects of practice. This research suggests that this specific and important area of learning and professional formation is often overlooked for individuals and could be more productively addressed within the work place. A greater emphasis on the supported practice of novice lecturers would enable experienced teaching staff as mentors, to provide extensive support for learning within the work based context. The university provided provision in isolation is not effective in delivering to the FE sector fully formed practitioners, nor should it be. As previously argued, both formal and informal work based learning (Eraut 2004) and effective mentoring (Cunningham 2007) are inextricably linked to the provision of effective teacher education programmes for lecturers in FE.

Of note are the challenges that these findings present to sector leaders, policy makers and perhaps most importantly, experienced practitioners. The expertise to support the developing and dynamic workforce already exists within college communities and with careful planning and investment could easily be deployed more effectively across the sector. The desire to support students who need extra guidance and specifically skilled lecturers is evident within the community of educators in FE. Equally, the lecturers informing this research showed that they were keen to provide practical and specialist pedagogic support to new colleagues. Of importance then is how mentors are specifically trained and deployed alongside a clarification of their roles as mediators.

It was clear from the college studied in Scotland that too few mentors offer an incomplete solution as trainee colleagues cannot access their mentor and equally the mentor has an unmanageable case load. The solution then is not just naming people as mentors but providing a resourced and targeted service that offers tangible benefits to both trainee and mentor that ties in seamlessly with other programmed courses of training provision.

As the future requirements for headline qualifications such as PG Cert and TQFE become increasingly uncertain the importance of mentors working in partnership within colleges is especially poignant. Given the devolved powers for the setting of standards and levels of required qualifications in England and Wales and the continued rationalisation of the Scottish FE sector, the role of work based learning supported by experienced mentors may become increasingly prominent. FE has been identified as a critical sector in the development of the UKs international strategy in the development of its skills economy and as such has recently received much scrutiny that has been lacking for many years. How colleges meet the nationally important challenges in the coming years will depend heavily on the emphasis given to professional learning and support for the many industrial experts that are expected to enter a second career as lecturers. These individuals all bring a rich and varied heritage, skill set, wealth of experience and enthusiasm to the sector and much more could and should be done to harness and emphasise this critical and extremely important set of qualities. This research has 
shown that a structured and multi-facetted approach to supporting professional learning, utilising the skills and experience of mentors, the academic community, and targeted work based learning may yield positive results for the whole sector.

\section{References}

Age, L. 2011. 'Grounded Theory Methodology: Positivism, Hermeneutics, and Pragmatism'. Qualitative Report 16 (6): 1599-1615.

Audit Scotland. 2015. 'Scotland's Colleges 2015'. Edinburgh.

Avis, J, and A Bathmaker. 2004. 'The Politics of Care : Emotional Labour and Trainee Further Education Lecturers'. Journal of Vocational Education \& Training 56 (1): 05-20.

Avis, J, B Morgan-klein, R Canning, and R Simmons. 2012. 'Teacher Education for Vocational Education and Training: A Comparative Study of the Scottish and English Systems Set within a European Context'. Scottish Educational Review 44 (2): 14-23.

BERA. 2018. Ethical Guidelines for Educational Research. London: British Educational Research Association.

Bowen, G. 2009. 'Document Analysis as a Qualitative Research Method'. Qualitative Research Journal 9 (2): 27-40. https://doi.org/10.3316/qrj0902027.

Bradshaw, M, and E Stratford. 2010. 'Qualitative Research Design and Rigour'. In Qualitative Research Methods in Human Geography, edited by I Hay, 69-80. Ontario: Oxford University Press.

Canning, R. 2011. 'Reflecting on the Reflective Practitioner: Vocational Initial Teacher Education in Scotland'. Journal of Vocational Education \& Training 63 (4): 609-17.

Coffield, F, D Moseley, E Hall, and K Ecclestone. 2004. Learning Styles and Pedagogy in Post 16 Learning: A Systematic and Critical Review. London: Learning and skills Research Centre.

Crist, J, and C Tanner. 2003. 'Interpretation/Analysis Methods in Hermeneutic Interpretive Phenomenology'. Nursing Research May/June 52 (3): 202-5. https://doi.org/10.1097/00006199_ 200305000-00011.

Cunningham, B. 2007. "All the Right Features: Towards an "architecture" for Mentoring Trainee Teachers in UK Further Education Colleges'. Journal of Education for Teaching 33 (1): 83-97. https://doi.org/10.1080/02607470601098351.

Drever, E. 2003. Using Semi-Structured Interviews. 2nd ed. Glasgow: University of Glagow.

Engestrom, Y. 2001. 'Expansive Learning at Work: Toward an Activity Theoretical Conceptualisation'. Journal of Education and Work 14 (1): 133-156.

Eraut, M. 2004. 'Informal Learning in the Workplace'. Studies in Continuing Education 26 (2): 24773. https://doi.org/10.1080/158037042000225245.

ETF. 2014. 'Professional Standards for Teachers and Trainers in Education and Training'. London: Education and Training Foundation.

Gadamer, H. 1976. Philosophical Heremeneutics. Berkeley: University of California Press. 1998. Truth and Method. 2nd ed. New York: Continuum.

Goh, A. 2013. 'The Significance of Social Relationships in Learning to Become a Vocational and Technical Education Teacher: A Case Study of Three Individuals'. Studies in Continuing Education 35 (3): 366-78. https://doi.org/10.1080/0158037X.2013.770390.

Heidegger, M. 1962. Being and Time. (Original. New York: Harper. 
IFL. 2007. New Overarching Professional Standards for Teachers, Tutors and Trainers in the Lifelong Learning Sector in Wales. Cardiff: Institute for Learning.

Institute for Learning. 2013. 'Should Teaching Qualifications Be Left to Chance ?' Edited by S Chowen. London: IfL.

Laverty, S. 2003. 'Hermeneutic Phenomenology and Phenomenology: A Comparison of Historical and Methodological Considerations'. International Journal of Qualitative Research 2 (3): 1-29.

Leivisk, A. 2015. 'The Relevance of Hans-Georg Gadamer' S Concept'. Educational Theory 65 (5): 581-600.

Lingfield, R. 2012. Professionalism in Further Education. London: Department for Further Education, Skills and Lifelong Learning, London.

Lucas, N, and L Unwin. 2009. 'Developing Teacher Expertise at Work: In-Service Trainee Teachers in Colleges of Further Education in England'. Journal of Further and Higher Education 33 (4): 423-33. https://doi.org/10.1080/03098770903272503.

Manen, M van. 1990. 'Hermeneutic Phenomenological Writing'. In Researching Lived Expeience, edited by P Smith, 111-33. New York: State University of New York Press.

Maxwell, B. 2014. 'Improving Workplace Learning of Lifelong Learning Sector Trainee Teachers in the UK'. Journal of Further and Higher Education 38 (3): 377-99. https://doi.org/10.1080/0309877X.2013.831036.

Orr, K. 2012. 'Coping, Confidence and Alienation: The Early Experience of Trainee Teachers in English Further Education'. Journal of Education for Teaching : International Research and Pedagogy 38 (1): 51-65.

PLDF. 2012. Professional Standards for Lecturers in Scotland's Colleges. Stirling: Professional Learning Development Forum.

Simmons, R. 2008. 'Golden Years? Further Education Colleges under Local Authority Control'. Journal of Further and Higher Education 32 (4): 359-71. https://doi.org/10.1080/03098770802395579.

Simon, M. 2011. Bracketing: Dissertation and Scholarly Research, Recipes for Success. Seattle: LLC.

Watson, J. 1971. 'Heidegger's Hermeneutic Phenomenology'. Philosophy Today 15 (1): 30-43.

Wenger, E, and J Lave. 2002. 'Legitimate Peripheral Participation in Communities of Practice'. In Supporting Life Long Learning, edited by J Clark R Harrison, F Reeve, A Hanson, 111-26. London: Routledge Falmer.

Woodd, M. 1997. 'Mentoring in Further and Higher Education: Learning from the Literature'. Education + Training 39 (9): 333-43. https://doi.org/10.1108/00400919710192368.

Yin, R. 2011. Qualitative Research from Start to Finish. London: The Guildford Press.

Zaidi, A, C Howat, and J Caisl. 2017. 'Initial Teacher Education Provision in Further Education'. London. 